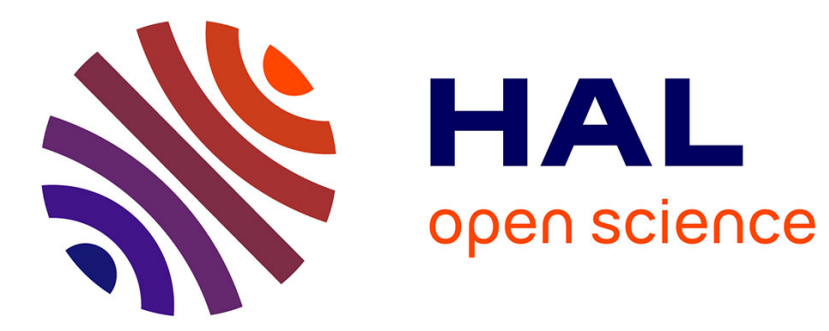

\title{
AZO electrodes deposited by atomic layer deposition for OLED fabrication
}

Benoit Dugrenil, Isabelle Séguy, H. y Lee, Thierry Camps, Y.-C. Lin, Jean Baptiste Doucet, Y.-S. Chiu, Ludovic Salvagnac, Eléna Bedel-Pereira, Marc Ternisien, et al.

\section{To cite this version:}

Benoit Dugrenil, Isabelle Séguy, H. y Lee, Thierry Camps, Y.-C. Lin, et al.. AZO electrodes deposited by atomic layer deposition for OLED fabrication. SPIE Photonics Europe, Apr 2014, Brussels, Belgium. pp.91371D. hal-01993226

\section{HAL Id: hal-01993226 \\ https://hal.laas.fr/hal-01993226}

Submitted on 24 Jan 2019

HAL is a multi-disciplinary open access archive for the deposit and dissemination of scientific research documents, whether they are published or not. The documents may come from teaching and research institutions in France or abroad, or from public or private research centers.
L'archive ouverte pluridisciplinaire HAL, est destinée au dépôt et à la diffusion de documents scientifiques de niveau recherche, publiés ou non, émanant des établissements d'enseignement et de recherche français ou étrangers, des laboratoires publics ou privés. 


\title{
AZO electrodes deposited by Atomic Layer Deposition for OLED Fabrication
}

\author{
B. Dugrenil ${ }^{\mathrm{a}, \mathrm{b}}$, I. Séguy ${ }^{\mathrm{a}, \mathrm{b}}$, H.Y. Lee ${ }^{\mathrm{c}, \mathrm{d}}$, T. Camps ${ }^{\mathrm{a}, \mathrm{b}}$, Y.-C. Lin ${ }^{\mathrm{c}, \mathrm{d}}$, J.B. Doucet ${ }^{\mathrm{a}, \mathrm{b}}$, Y.-S. Chiu ${ }^{\mathrm{c}, \mathrm{d}}$, L. \\ Salvagnac $^{\mathrm{a}, \mathrm{b}}$, E. Bedel-Pereira ${ }^{\mathrm{a}, \mathrm{b}}$, M. Ternisien ${ }^{\mathrm{e}}$, C.T. Lee ${ }^{\mathrm{c}, \mathrm{d}}$ and V. Bardinal*a,b \\ ${ }^{a}$ CNRS ; LAAS ; 7 avenue du colonel Roche, F-31077 Toulouse, France \\ ${ }^{\mathrm{b}}$ Univ de Toulouse ; UPS, INSA, INP, ISAE ; LAAS ; F-31077 Toulouse, France \\ ${ }^{\mathrm{c}}$ Department of Photonics, National Cheng Kung University, Tainan 701, Taiwan, Republic of China \\ ${ }^{\mathrm{d}}$ Institute of Microelectronics, Department of Electrical Engineering, National Cheng Kung University, Tainan 701, \\ Taiwan, Republic of China \\ ${ }^{e}$ LAPLACE, Université Paul Sabatier, 118 Route de Narbonne, 31062 Toulouse, France
}

\begin{abstract}
In this work, we present a comparative study of optimized AZO electrodes deposited by Atomic Layer Deposition (ALD) with commercial ITO in terms of electrical, optical and structural properties. Despite a lower figure of merit mainly due to a higher sheet resistance, AZO-based OLEDs are shown to present a current density five times higher than ITO-based ones for the same applied voltage. These AZO electrodes fabricated by ALD could thus be promising substitutes for conventional ITO anodes in organic electronic devices.
\end{abstract}

Keywords: Transparent Conductive Oxide, aluminium-doped Zinc Oxide, Atomic Layer Deposition, Organic Light Emitting Diodes, Indium Tin Oxide

\section{INTRODUCTION}

Transparent conducting oxide (TCO) films are widely utilized as electrodes in various optoelectronic devices, including flat panel displays, organic light emitting diode (OLED), and photovoltaic. The dominant material used as TCO films is indium tin oxide (ITO), due to its low resistivity and high transmittance in visible wavelength [1]. However, the cost of using indium, as a dopant is high due to its scarce characteristic and it degrades the performance of OLEDs due to its diffusion into the organic materials [2]. Therefore, various TCOs, such as $\mathrm{ZnO}$ (zinc oxide) based TCO [1], conducting polymer [3], nanometal and carbon nanotubes [4][5], have been investigated and applied in OLEDs. Among them, Aldoped zinc oxide (AZO) films are favourable materials as an alternative TCO film owing to their low cost, nontoxic, and relative abundance. AZO films have been deposited by several deposition techniques, including radio frequency sputtering [1], pulsed laser deposition [6] and chemical vapour deposition. In this work, AZO films are deposited by atomic layer deposition (ALD) system to exploit several advantages, including high uniformity on large area, low deposition temperature and accurate thickness control. Because of the self-limiting surface reaction mechanism of ALD, the thickness and doping concentration can be easily controlled by the number of ALD cycles. Consequently, the high uniform and conductivity of AZO film in large area has a great potential to improve various devices in future. 


\section{AZO FABRICATION BY ALD}

The electrical and optical properties of the semiconducting oxides like AZO, depend on their preparation and growth conditions. In this work, $230 \mathrm{~nm}$ thick AZO films are deposited on glass substrates by atomic layer deposition (ALD) system. The precursors of diethylzinc (DEZn), trimethylaluminum (TMAl) and water $\left(\mathrm{H}_{2} \mathrm{O}\right)$ are used as zinc (Zn), aluminum $(\mathrm{Al})$, and oxygen $(\mathrm{O})$ sources, respectively. The chamber pressure of 0.6 torr and the substrate temperature of $200^{\circ} \mathrm{C}$ are fixed, respectively. In each cycle, the pulse time of DEZn, TMAl, and $\mathrm{H}_{2} \mathrm{O}$ is 0.5 s. After each step of reactant, argon (Ar) gas is utilized as the carrier gas for $3 \mathrm{~s}$. In this work, the AZO film is repeatedly deposited by stacking $\mathrm{X}$ zinc oxide cycles ( $\mathrm{X}$ represents the $\mathrm{ZnO}$ :AlO cycle ratio and its values lie between 13 and 25 ) and one aluminum oxide cycle. Then thermal annealing is performed to obtain Al-doped $\mathrm{ZnO}$ films and enhance their electrical and optical properties.

\section{AZO CHARACTERIZATION}

\subsection{Electrical characterizations}

The electrical properties of AZO films are measured by HMS-5000 Hall effect system. The carrier concentration, mobility and resistivity for different $\mathrm{X}$ values varying between 13 and $25 \mathrm{ZnO}$ :AlO cycle ratio are reported in table 1 . In this table we can observe that the lowest resistivity is obtained for the 20:1 AZO sample. OLED applications impose using of TCO films with low resistivity, so according to the above result, an optimum ZnO:AlO cycle ratio for AZO films deposited by ALD is achieved.

Table 1: Hall charge concentration, carrier mobility and resistivity of the AZO thin films as a function of the ZnO:AlO cycle ratio.

\begin{tabular}{|c|c|c|c|c|}
\hline $\begin{array}{c}\text { Substrate } \\
\text { temperature }\end{array}$ & $\begin{array}{c}\text { Cycle ratio } \\
(\mathrm{ZnO} \text { AlO) }\end{array}$ & $\begin{array}{c}\text { Electron } \\
\text { Concentration } \\
\left(\mathrm{cm}^{-3}\right)\end{array}$ & $\begin{array}{c}\text { Electron } \\
\text { mobility } \\
\left(\mathrm{cm}^{-2} . \mathrm{V}^{-1} . \mathrm{s}^{-1}\right)\end{array}$ & $\begin{array}{c}\text { Resistivity } \\
(\Omega . \mathrm{cm})\end{array}$ \\
\hline \multirow{3}{*}{$200{ }^{\circ} \mathrm{C}$} & Undoped ZnO & $2.71 \times 10^{19}$ & 7.32 & $3.1 \times 10^{-2}$ \\
\cline { 2 - 5 } & $13: 1$ & $2.78 \times 10^{21}$ & 2.98 & $8.71 \times 10^{-4}$ \\
\cline { 2 - 5 } & $15: 1$ & $2.67 \times 10^{21}$ & 3.7 & $6.41 \times 10^{-4}$ \\
\cline { 2 - 5 } & $20: 1$ & $2.51 \times 10^{21}$ & 3.98 & $6.24 \times 10^{-4}$ \\
\cline { 2 - 5 } & $25: 1$ & $2.4 \times 10^{21}$ & 4.2 & $6.42 \times 10^{-4}$ \\
\hline
\end{tabular}

In order to improve TCO electrical properties, post-annealing treatments in hydrogen ambience for 30 minutes have been performed. Among films studied by Hall effect, we choose the $200^{\circ} \mathrm{C}$ annealed $20: 1 \mathrm{AZO}$ as a possible promising substitute for conventional ITO anodes since it shows the lowest resistivity value, $4.52 \times 10^{-4} \Omega$.cm. Sheet resistance uniformity of this film is then checked by four points probe mapping on a five inches wafer. The mean sheet resistivity of 20:1 AZO film is found close to $54 \Omega$ /sq, ie slightly higher than that of usual commercial ITO (Table 2). These results are confirmed by resistivity mapping measurements on 4 inches diameter wafers using a 4-probes electrical set-up, demonstrating a very good uniformity of the deposited layer. 


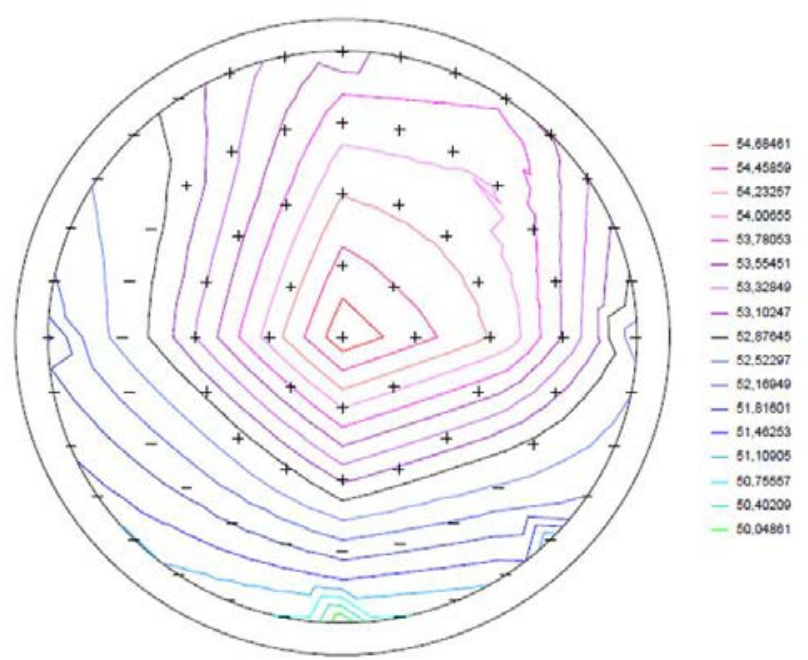

Figure 1: Sheet resistivity contour map $(\Omega / \mathrm{sq})$ of AZO films deposited on a 4 inches glass wafer measured with a 4 -probes set-up

\subsection{Optical characterizations}

To further investigate the optical properties of 20:1 AZO films, transmittance between 450 and $800 \mathrm{~nm}$ is measured by FTIR Bruker spectrometer. In Figure 2, we present the transmittance spectra of 230nm-thick AZO film. We can notice that transmittance is higher than $80 \%$ in the green part of the visible range. In TCO, electrical and optical optimization plays a key role. Both conductivity and transmittance should be as high as possible. However, they are inversely correlated to each other. Hence the optimum value of these two parameters should be established using figure of merit. The most commonly used definition of figure of merit, $\phi_{\mathrm{TC}}$, of a transparent conducting film was first given by G. Haacke [7] as:

$$
\Phi_{\mathrm{TC}}=\mathrm{T}^{10} / \mathrm{R}_{\mathrm{sh}}
$$

where $\mathrm{T}$ is the transmittance at a particular wavelength and $\mathrm{R}_{\mathrm{sh}}$ is the sheet resistance.

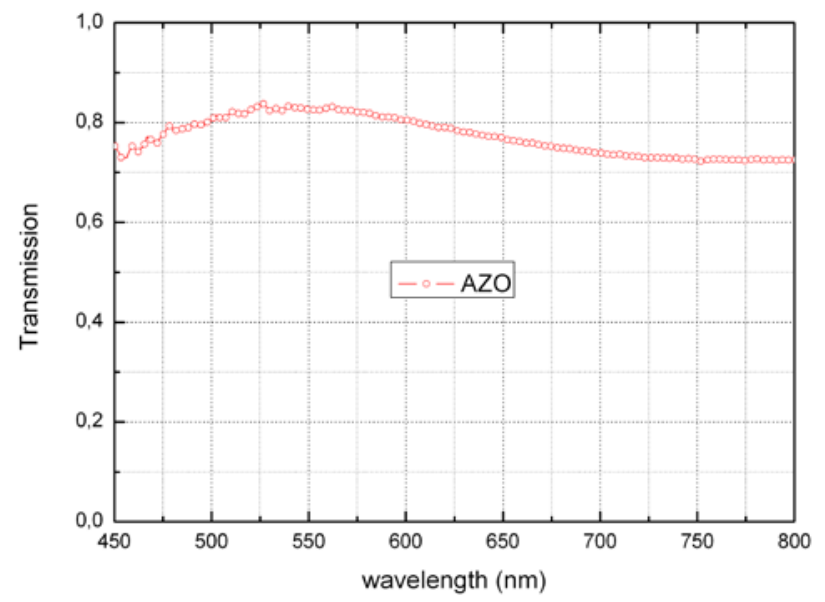

Figure 2: Optical transmission spectrum of 20:1 AZO thin film deposited by ALD. 
The transmission value at 550nm (corresponding to the targeted OLED maximum emission wavelength) is extracted from this spectrum: $82.7 \%$. This has to be compared to $86 \%$ measured for $120 \mathrm{~nm}$-thick ITO commercial film (from OSSILA Limited) used as a reference. The determined figures of merit for AZO and commercial ITO thin films can be then calculated at $550 \mathrm{~nm}: 2.8$ and $13\left(10^{-3} . \Omega^{-1}\right)$ respectively. This indicates that AZO electrical and optical properties are slightly inferior to those of commercial ITO. Nevertheless, this TCO could fulfill the qualifications for OLED applications.

\subsection{Structural characterizations}

Beyond electrical and optical properties, TCO requirements for OLED include surface film roughness and homogeneity. Atomic Force Microscopy (AFM) and Scanning Electron Microscopy (SEM) were used to observe surface morphology of AZO. Figure 3 shows the two-dimensional surface morphology AFM and SEM images of the AZO 20:1 thin film. It is obvious that the surface of this film exhibits a very smooth profile. The measured RMS roughness is $1.7 \mathrm{~nm}$. From the three-dimensional surface morphology images (not shown here), it can be seen that AZO thin films include columnar grains, which can be also observed by SEM.
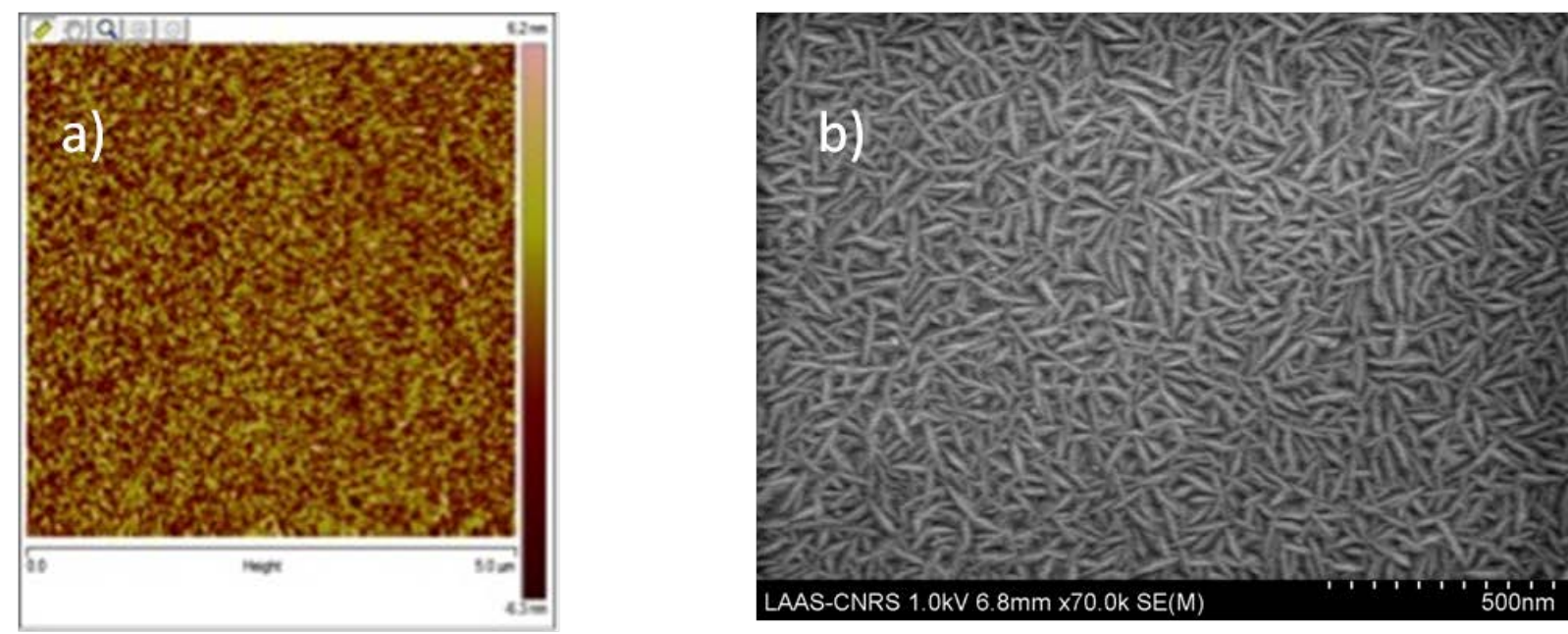

Figure 3: 20:1 AZO film surface characterization: (left)AFM on $5 \mathrm{X} 5 \mu \mathrm{m}^{2}$ surface and (right) SEM images.

\section{AZO-BASED OLEDS}

\subsection{OLEDs fabrication}

To investigate AZO film as anode in OLEDs, simple devices made of either AZO or commercial ITO films are fabricated in order to compare their electrical performances. OLEDs are fabricated on AZO or ITO coated glass substrates and have the following configurations: glass/AZO or ITO/N,N'-Bis(naphthalen-1-yl)-N,N'bis(phenyl)benzidine(NPB) (50nm)/tris(8-hydroxyquinoline) aluminum ( $\left.\mathrm{Alq}_{3}\right)(50 \mathrm{~nm}) / \mathrm{Al}(150 \mathrm{~nm})$. First, circles of TCO are patterned by chemical etching using conventional photolithography. Then, organic films are deposited onto cleaned anodes, at a pressure of $10^{-7}$ Torr in PLASSYS MEB550B equipment. The chemicals are placed in organic material effusion cells located $30 \mathrm{~cm}$ below the substrate. The deposition rate of the evaporated materials $0.03 \mathrm{~nm} . \mathrm{s}^{-1}$ and the thickness of each layer $50 \mathrm{~nm}$ are controlled by quartz vibrating thickness monitor placed near the samples. The upper electrodes are obtained by evaporation of $150 \mathrm{~nm}$ aluminium films through an appropriate mask. The active area 
of each individual component is equal to $3 \mathrm{~mm}^{2}$. Prior to characterization, OLEDs are kept in a dry glove box under nitrogen atmosphere.

\subsection{Electrical characterizations and comparison with ITO}

Electrical characterisation of OLEDs is made under ambient atmosphere using a 2450 Keithley electrometer. The J-V characteristics of the investigated devices are presented in figure 4 . Current density reaches values as high as 0.25 and $0.08{\mathrm{~A} . \mathrm{cm}^{-2}}^{2}$ for AZO and ITO respectively at $20 \mathrm{~V}$ (Fig. 4.a).

All other factors being equal, it is reasonable to suppose that the highest current density at a given voltage measured in AZO based device reveals the true effect of the anode nature on hole injection. In our case the use of AZO anode with work function slightly greater than that of commercial ITO (see table 2) probably lowers hole injection barrier and improve the OLED turn-on voltage. However we must notice that charge injection efficiency does not only depends upon electrodes work function but also upon surface structure and electronic states at interfaces.
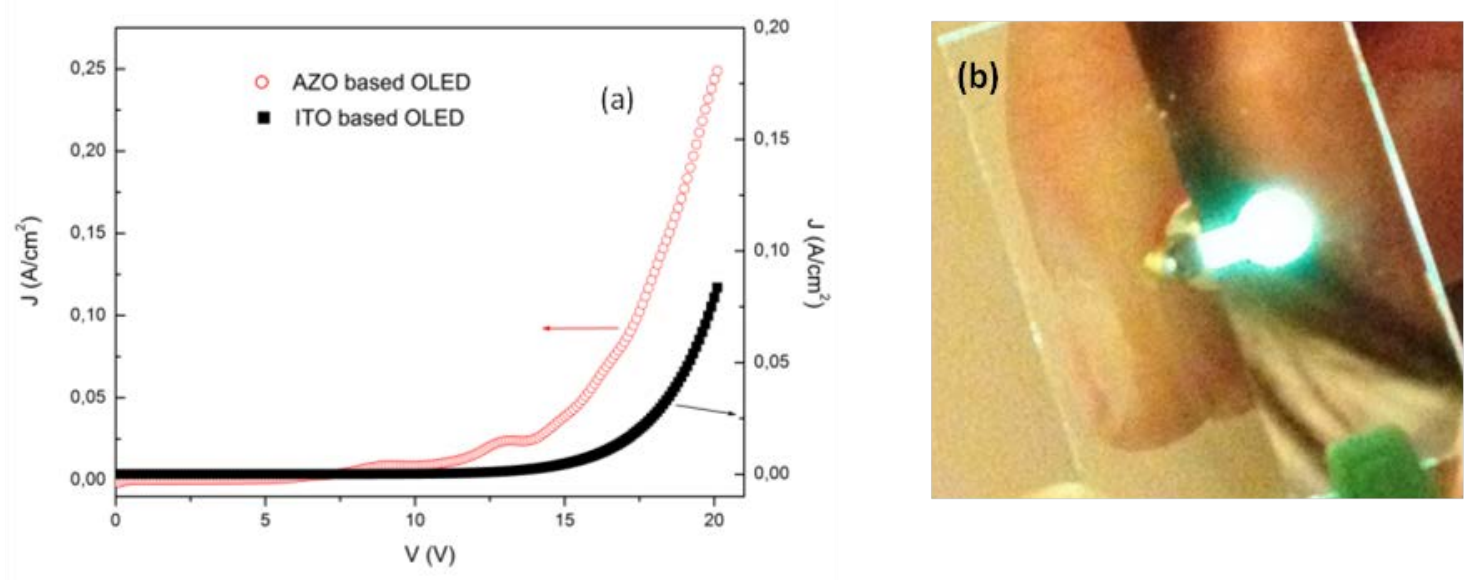

Figure 4: (a) Comparison of NPB/Alq3 based OLED electrical efficiencies J(V) with AZO and commercial ITO anodes (b) Image of AZO-based OLED emitting under 15V applied.

Figure 4b illustrates the bright green emission from a typical AZO-based device under 15V applied, demonstrating the ability of our AZO electrodes to be used for OLED fabrication. It is worth noting that emission is uniform over the entire active area of the device, as it is observed for ITO-based devices. Precise optical characterization of AZO and ITO-based OLEDs electroluminescence is currently undergoing using a dedicated set-up (with an integrating sphere sensor) in order to achieve a precise comparison of global respective efficiencies.

Table 2: Summary of TCO and OLED electrical characteristics

\begin{tabular}{|c|c|c|c|c|c|}
\hline TCO materials & $\begin{array}{c}\text { Work function } \\
(\mathrm{eV})\end{array}$ & $\begin{array}{c}\text { Sheet } \\
\text { resistance } \\
(\Omega / \mathrm{sq})\end{array}$ & $\begin{array}{c}\text { Thickness } \\
(\mathrm{nm})\end{array}$ & $\begin{array}{c}\Phi_{\text {TC }} \text { at } 550 \mathrm{~nm} \\
\left(10^{-3} \cdot \Omega^{-1}\right)\end{array}$ & $\begin{array}{c}\text { Current } \\
\text { density at } \\
20 \mathrm{~V}\left(\mathrm{~A} / \mathrm{cm}^{2}\right)\end{array}$ \\
\hline AZO & 4.9 & 54 & 230 & 2.8 & 0.25 \\
\hline TO & 4.5 & 17 & 120 & 13 & 0.08 \\
\hline
\end{tabular}




\section{CONCLUSIONS}

In this study, AZO layers with different $\mathrm{ZnO}$ :AlO cycle ratios are deposited onto glass substrates by using an ALD deposition system. The influences of $\mathrm{ZnO}$ :AlO cycle ratio on their electrical performances have been investigated by Hall effect. The electrical, optical and morphological properties of for 20:1 AZO thin film demonstrate the applicability of this TCO as effective OLED anode, despite a lower figure of merit compared to commercial ITO. Moreover, electrical comparison of AZO with ITO based devices indicates that AZO-based OLEDs exhibit higher current density at the same applied voltage. Future work will deal with the comparison of the electroluminescence of both OLEDs. In conclusion, we suggest that the AZO films prepared by ALD deposition are indium free anodes that present several advantages such as good transmittance, uniform surface, and high work function without any surface treatment.

\section{ACKOWLEDGEMENTS}

The authors gratefully acknowledge CNRS (France) and NSC (Taiwan, Rep. of China) for financial support and RENATECH (French Network of Major Technology Centres) within LAAS-CNRS for technological support. The authors would also like to thank Mr. Gautier Petit and Mr. Bernard Franc for their contribution to electrical measurements.

\section{REFERENCES}

[1] Y. Igasaki, H. Kanma, “Argon gas pressure dependence of the properties of transparent conducting ZnO:Al films deposited on glass substrates” Appl. Surf. Sci., vol. 169-170, 508 (2001).

[2] N.P. Dasgupta, S. Neubert, W. Lee, O. Trejo, J.-R. Lee and F. B. Prinz, « Atomic Layer Deposition of Al-doped ZnO Films: Effect of Grain Orientation on Conductivity” Chem. Mater., vol. 22, 4769 (2010).

[3] Y.-J. Choi, S. C.Gong, C.-S. Park, H.-S. Lee, J. G. Jang, H. J. Chang, G. Y. Yeom, and H.-H. Park, "Improved Performance of Organic Light-Emitting Diodes Fabricated on Al-Doped ZnO Anodes Incorporating a Homogeneous Al-Doped ZnO Buffer Layer Grown by Atomic Layer Deposition” Appl. Mater. Interfaces, vol. 5, 3650-3655 (2013).

[4] J. W. Huh, Y. M. Kim, Y. W. Park, J. H. Choi, J. W. Lee, J. Woo Lee, J. W. Yang, S. H. Ju, K. K.Paek and B. K. Ju, "Characteristics of organic light-emitting diodes with conducting polymer anodes on plastic substrates", J. Appl. Phys. vol. 103, 044502 (2008).

[5] C.M. Aguirre, S. Auvray, S. Pigeon, R. Izquierdo, P. Desjardins, and R. Martel "Carbon nanotube sheets as electrodes in organic light-emitting diodes”, Appl. Phys. Lett., 88, 183104 (2006).

[6] M. Hiramatsu, K. Imaeda, N. Horio, M, Nawata, “Transparent conducting ZnO thin films prepared by XeCl excimer laser ablation “ J. Vac. Sci. Technol. A, vol. 16, 669 (1998).

[7] G. Haacke, “New figure of merit for transparent conductors “ J. Appl. Phys. 47, 4086 (1976). 